\title{
Ship Components, Cargo, or Contamination: Determining the Origin of Wood Fragments Recovered from an Underwater Shipwreck Site
}

\author{
M. W. Pendleton,* B. B. Pendleton,** G. Fox, ${ }^{* * *}$ E. A. Ellis,* and T. C. Stephens* \\ * Microscopy and Imaging Center, Texas A\&M University, College Station, TX. 77843-2257 \\ ** Division of Agriculture, West Texas A\&M University, Canyon, TX. 79016-0001 \\ *** Museum of Anthropology, California State University, Chico, CA 95929-0400
}

The characteristics of two wood samples (labeled A and B) recovered in August 1991 from an underwater shipwreck site (fig. 1) near the town of Dodos Greece are described using images obtained by scanning electron microscopy (SEM). This underwater site was located in the Bay of Skindos in the Aegean Sea and was dated to 2200 B.C. The wood samples were analyzed to determine if they were associated with the wreck structure, or the wreck cargo, or were modern debris brought into the site by ocean current activity.

The wood samples were transported from the wreck site in vials of seawater and then placed through an alcohol series (20\% steps to $100 \%)$ prior to critical point drying with a Denton CP-1. After drying, the wood samples were coated with 600 angstroms of gold palladium using a Hummer II sputter coater and observed using a JEOL JSM-6400 scanning electron microscope. Features of the samples were entered into the General Unknown Entry and Search System (GUESS) program for computer-aided wood identification [1]. The program used coded features described with photos and drawings [2]. The vestured pit features noted on sample A (fig. 2) were similar to the pits present in Eugenia cluseaefolia (a member of the Myrtaceae family) described in the coded features system of the GUESS program.

When recovered from the wreck, the outer surface of both wood samples was covered with debris. To obtain images of the dried wood surfaces, which were free of debris, the samples were split and the cleaved surfaces were examined. Wood sample A (fig. 3) had no debris and/or crystals in vessels on the cleaved sections so sample A was probably a modern wood fragment that had been washed into the shipwreck site. Wood sample B (fig. 4) had debris and/or crystals in the vessels on cleaved surfaces so sample B may have been associated with the shipwreck as part of the structural timber or cargo. Many of the crystals noted in sample B were similar to those described by Barbour and Leney [3] as cellulose in crystalline form. Not only were the vessel elements of sample B filled with debris and crystals but bacterial activity had produced small holes in the vessel elements. This type of bacterial damage has been observed in submerged timber from a wrecked Chinese ship sunk over 700 years ago [4].

References.

[1] C. A. LaPasha, N. Carolina Agric. Res. Bul. 474A (1986).

[2] E. A. Wheeler et al., N. Carolina Agric. Res. Bul. 474 (1986).

[3] R. Barbour and L. Leney, Papers Presented at the Sixth International Biodeterioration

Symposium, Washington, D. C. 1984, C. A. B. International, Slough, United Kingdom, 1986.

[4] Y. S. Kim, The International Research Group of Wood Preservation. I. R. G. Secretariat, Stockholm, Sweden, 1987. 


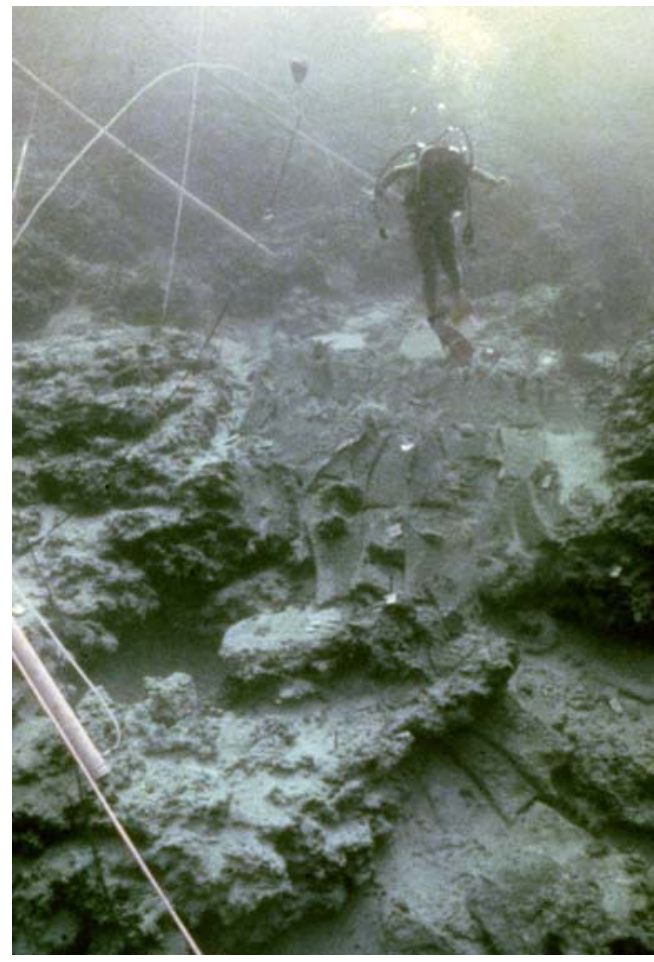

Fig. 1. Diver and shipwreck site

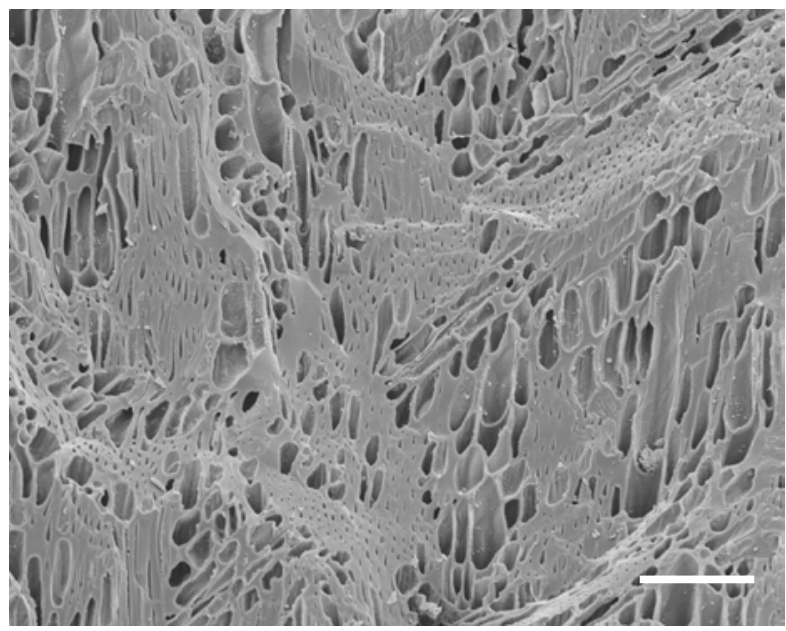

Fig. 3 (SEM). Cross-section of Sample A. These vessels are not filled with debris and crystals and the walls appear smooth. Scale bar $=50 \mu \mathrm{m}$.

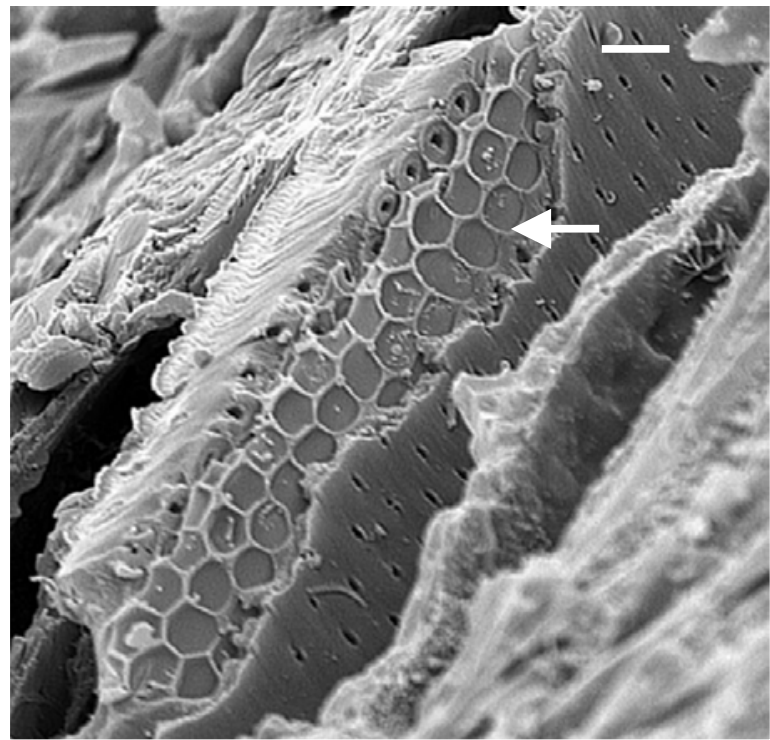

Fig. 2 (SEM). Sample A internal vessel area visible due to breakage of upper cell layers (arrow). This structure is similar to vestured pits observed in Eugenia cluseaefolia, a member of the Myrtaceae family. Scale bar $=8 \mu \mathrm{m}$.

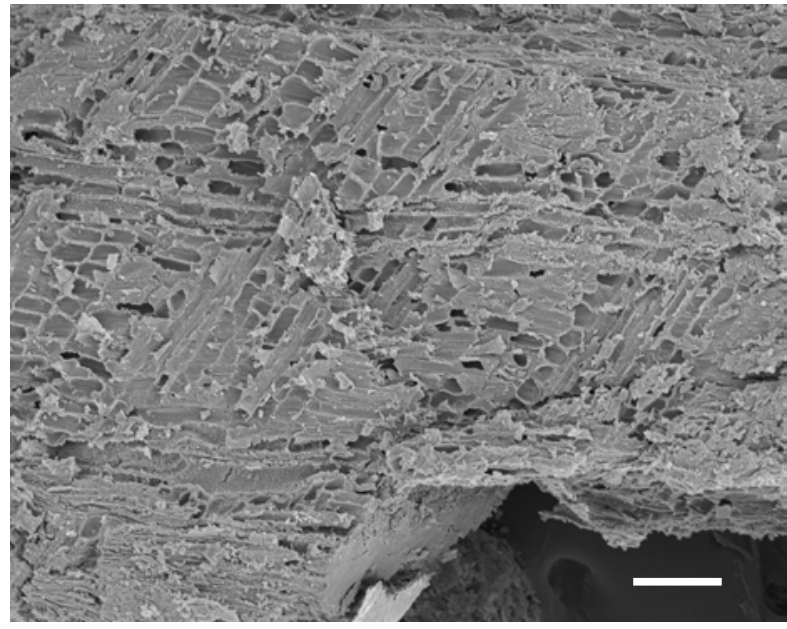

Fig. 4 (SEM). Cross-section of Sample B. These vessels are filled with debris and crystals which are probably cellusose in crystalline form. Scale bar $=50 \mu \mathrm{m}$. 